\title{
COURSE OF DISTRESS AND QUALITY OF LIFE IN TESTICULAR CANCER PATIENTS BEFORE, DURING, AND AFTER CHEMOTHERAPY: RESULTS OF A PILOT STUDY
}

\author{
PETER C. TRASK ${ }^{\mathrm{a}, *}$, AMBER G. PATERSON ${ }^{\mathrm{a}}$, JUDITH FARDIG $^{\mathrm{b}}$, and DAVID C. SMITH \\ ${ }^{a}$ Behavioral Medicine Program, University of Michigan, USA \\ ${ }^{\mathrm{b}}$ Department of Internal Medicine, University of Michigan, USA
}

\begin{abstract}
SUMMARY
Testicular cancer is the most common cancer in white males between the ages of 15 and 45 years. Treatment may include the administration of chemotherapy which has been associated with changes in emotional distress, quality of life, and symptom distress in other cancers. The current study was designed to evaluate the course of these constructs in a sample of testicular cancer patients undergoing chemotherapy. Patients completed measures of emotional distress and quality of life prior to, during, and after chemotherapy, with symptom distress measured during chemotherapy. Thirty percent of patients reported moderate to high levels of distress at pre-treatment baseline that was associated with worse quality of life. Initial anxiety and distress decreased and stayed low through chemotherapy and post-treatment follow-up. There were no significant changes in fatigue, nausea or change in appearance during chemotherapy. The results suggest that some patients evidence pre-treatment anxiety and distress that appears to be primarily anticipatory, decreases over the course of chemotherapy, and occurs in the context of improved quality of life and reduced symptom severity. Deleterious changes in emotional distress, quality of life, and symptom distress seen in other cancer populations were not apparent in our sample of testicular cancer patients. Copyright (C) 2003 John Wiley \& Sons, Ltd.
\end{abstract}

\section{INTRODUCTION}

Testicular cancer is the most common cancer in white males between the ages of 15 and 45 years, accounting for almost a quarter of the cancers in that age group. The 5-year survival rates for both stage 1 and 2A/B seminomatous and nonseminomatous testicular germ cell tumors (NSGCTT) are extremely high, averaging between 90 and $100 \%$ (Heidenreich and Hofmann, 1999). 5-year survival

\footnotetext{
*Correspondence to: Peter C. Trask, PhD. Research Investigator, Behavioral Medicine Program, University of Michigan, 475 Market Place, Suite L Ann Arbor, MI 48108-0757, USA. E-mail: pctrask@umich.edu
}

rates for patients with advanced lymph node involvement are greater than $80 \%$, and the majority of patients with metastatic disease are cured using chemotherapy. In addition to the increased survival afforded by treatments over the last decade, refinements in techniques and therapies have reduced the iatrogenic effects (e.g. retrograde ejaculation, severe nausea) which accompanied earlier treatments for this disease. This is particularly true for chemotherapy where the development of newer antiemetics have allowed patients to receive therapy in the outpatient setting.

Chemotherapy frequently starts shortly following the initial orchiectomy, with one study reporting that $90 \%$ of patients start chemotherapy within 2 months post-orchiectomy. Current 
chemotherapy protocols use combinations of bleomycin, etoposide, and cisplatin (the BEP regimen) (Brada et al., 1987; Dearnaley et al., 1991; Williams and Einhorn, 1982). For individuals with NSGCTT, three courses of BEP are usually sufficient, with the cycles repeated every 21 days (Cullen et al., 1996).

While it frequently increases survival rates, chemotherapy in cancer patients has been found to exert significant physical effects as well. Common physical side effects during the course of treatment include nausea and vomiting, alopecia, fatigue, anorexia, mouth and gastric ulceration, diarrhea, neuropathy, and sexual problems (e.g. sterility, decreased desire) (Golden et al., 1980; Penman et al., 1984). In addition, chemotherapy often results in depression, anger, and anxiety (Arai et al., 1996; Freidenbergs et al., 1980; Meyerowitz, 1980). In some patients, nausea and anxiety occur prior to in addition to following chemotherapy (Bovbjerg et al., 1990; Nesse et al., 1980; Redd et al., 1982; van Komen and Redd 1985). Given the potential side effects, it is possible that chemotherapy may increase emotional distress and decrease quality of life.

Surprisingly, more extensive investigations into changes in emotional distress and quality of life have not been conducted with testicular cancer patients. The majority of studies that have been conducted have focused on psychosocial variables following the completion of treatment and not changes that occur during treatment. Moreover, most of these studies have been retrospective in nature. Few, if any, have included pre-treatment baseline and follow-up assessments. Studies evaluating distress in cancer patients throughout the course of chemotherapy have found that anticipatory anxiety is higher before the first chemotherapy cycle, and state anxiety is related to the presence of somatic side effects (e.g. post-treatment nausea) (Andrykowski et al., 1985; Jacobsen et al., 1993). Thus far, however, studies have focused on other forms of cancer (e.g. breast, ovarian) and have not investigated the effects of chemotherapy in testicular cancer. As such, the purpose of this pilot study was to: (1) identify the course of emotional health and quality of life in testicular cancer patients before, during, and after chemotherapy, and (2) assess the degree of symptom distress in patients during the course of chemotherapy. It was hypothesized that emotional distress/anxiety would be higher at the start of chemotherapy, that symptom distress would increase and be correlated with emotional distress over the course of chemotherapy, and emotional and symptom distress would be negatively correlated with $\mathrm{OOL}$

\section{METHODS}

\section{Subjects}

Between January 1999 and June 2001, 16 males scheduled to begin chemotherapy for testis cancer who were over the age of 18 years of age were approached, with all agreeing to participate in this pilot study. All patients provided written informed consent. The study and consent form were reviewed and approved by the University of Michigan Institutional Review Board. Patients ranged in age from 20 to 47 years $(X=31.25$, S.D. $=8.95)$. Table 1 presents the demographic data, stage of disease, and histopathological type for all patients.

\section{Chemotherapy}

Individuals on average underwent 3 cycles of chemotherapy with the BEP regimen over a span of 9 weeks on an outpatient basis at the University of Michigan Comprehensive Cancer Center. The cycles included daily treatment during the first week, and then treatment once/week for the next two weeks, with the cycle repeating itself on the $22 \mathrm{nd}$ and 44 th day. Treatment was provided by a team of medical professionals led by two physicians, a nurse practitioner and a physician assistant. Chemotherapy was delivered in the outpatient infusion area of the University of Michigan Comprehensive Cancer Center by chemotherapy certified nurses. Subjects received a standard antiemetic regimen consisting of a 5-HT3 receptor antagonist (granisetron or ondansetron) and dexamethasone. Prochlorperazine, thiethylperazine and lorazepam were used on an as needed basis.

\section{Instruments}

Brief Symptom Inventory (BSI): The BSI is a 53-item measure of emotional distress 
Table 1. Characteristics of testicular cancer patients

\begin{tabular}{|c|c|c|}
\hline & $\begin{array}{l}\text { Range } \\
\text { (median) }\end{array}$ & $\begin{array}{l}N \\
(\%)\end{array}$ \\
\hline \multicolumn{3}{|l|}{ Disease } \\
\hline Time since orchiectomy (months) & $1-13(2)$ & \\
\hline \multicolumn{3}{|c|}{ Retroperitoneal lymph node dissection } \\
\hline Pre-chemotherapy & & $3(18.8)$ \\
\hline Post-chemotherapy & & $6(37.5)$ \\
\hline \multicolumn{3}{|l|}{ Stage of Disease } \\
\hline Resected, no residual & & $1(6.2)$ \\
\hline Small volume & & $12(75)$ \\
\hline Large or very large volume & & $3(18.8)$ \\
\hline \multicolumn{3}{|l|}{ Histology } \\
\hline Seminoma & & $3(18.8)$ \\
\hline Nonseminoma & & $13(81.2)$ \\
\hline \multicolumn{3}{|l|}{ Chemotherapy } \\
\hline Number of cycles & $2-4(3)$ & \\
\hline Cisplatin/etoposide/bleomycin & & $15(93.8)$ \\
\hline Ciplatin/etoposide & & $1(6.2)$ \\
\hline \multicolumn{3}{|l|}{ Social } \\
\hline \multicolumn{3}{|l|}{ Martial status } \\
\hline Married & & $7(43.8)$ \\
\hline Never married & & $9(56.3)$ \\
\hline \multicolumn{3}{|l|}{ Race } \\
\hline Caucasian & & $14(87.5)$ \\
\hline Other & & $2(12.5)$ \\
\hline \multicolumn{3}{|l|}{ Education } \\
\hline High school graduate & & $6(37.5)$ \\
\hline Some college & & $4(25)$ \\
\hline College graduate & & $3(18.8)$ \\
\hline Professional/graduate school & & $3(18.8)$ \\
\hline \multicolumn{3}{|l|}{ Employment } \\
\hline Employed for hourly wages & & $9(56.3)$ \\
\hline Self-employed & & $2(12.5)$ \\
\hline Student & & $2(12.5)$ \\
\hline Medically disabled & & $1(6.3)$ \\
\hline Other & & $2(12.5)$ \\
\hline
\end{tabular}

which takes between 5 and $10 \mathrm{~min}$ to complete (Derogatis, 1992; Derogatis and Melisaratos, 1983). It has well-demonstrated reliability and validity (Boulet and Boss, 1991). Individual items are answered on a '0' (not at all distressed) to '4' (extremely distressed) scale and are summed into one of the nine clinical scales and three summary scales. One of these, the General Severity Index (GSI), provides a sensitive measure of overall distress. The BSI is standardized using area $t$-scores, each with a mean of 50 and a standard deviation of 10 . Area $t$-scores $>1$ S.D., above the mean have been identified as representative of moderate to clinically significant distress.

Functional Assessment of Cancer TreatmentGeneral (FACT-G): The FACT-G is a 47 -item questionnaire assessing quality of life (Cella et al., 1993; Cella, 1994). It is composed of five scales: physical well-being social/family well-being emotional well-being functional well being, and relationship with doctor. It has demonstrated reliability and validity. Lower scores on the FACT-G represent poorer QOL.

Symptom Distress Scale (SDS): The SDS is a 10-item 5-point scale that asks patients to rate the number that best corresponds to physical feelings (e.g. feeling sick, tired, bowel problems, appearance) commonly felt in response to chemotherapy 'during the past week including today'. Each item ranges from ' 1 -no problems' to 65 - the worst possible problems' in each area. Items can be totaled to obtain an overall symptom distress scale, with higher scores indicating more distress. The reliability coefficient alpha has been reported as 0.821 with the standardized item alpha reported as 0.5826 indicating food reliability (McCorkle and Young, 1978).

\section{Procedure}

After providing consent, all participants completed written self-report questionnaires timed to coincide with regular clinic visits. Patients completed a pre-treatment baseline questionnaire package that included a demographic questionnaire, the BSI, and the FACT-G. On the first day of each treatment cycle, patients completed the BSI, FACT-G, and SDS, before pre-medication for chemotherapy. Subsequently completion of the BSI and FACT-G occurred during clinic follow-up visits 3- and 8-months after patients completed chemotherapy. As such patients completed six assessments over the course of the study.

Statistical analyses were performed using SPSS 10.0 (Chicago, IL). Associations between continuous variables were computed using Pearson's product moment correlation coefficient. Longitudinal comparisons of measures from baseline through chemotherapy were computed using repeated measures analysis of variance (ANOVA). Comparisons of scores on measures following the last chemotherapy with 3- and 8-month follow-up utilized paired $t$-tests. 


\section{RESULTS}

\section{Baseline distress and quality of life}

As a group, individuals with testicular cancer did not demonstrate significantly increased mean levels of distress or significantly lower mean quality of life ratings compared with published normative data on the BSI and FACT-G. There was, however, considerable variability in these responses. Approximately $30 \%(5 / 16)$ of the sample reported scores greater than 60 on the GSI scale. Moreover, GSI scores were negatively correlated with the social/family well-being $(r=-0.68$, $p<0.01)$ and emotional well-being $(r=-0.56$, $p<0.05$ ) scales of the FACT-G, along with the FACT-G total score $(r=-0.54, p<0.05)$. Similar results were observed for the Depression, Hostility, and Somatization scales of the BSI (all $p<0.05$ ).

\section{Distress and quality of life during and after chemotherapy}

The results of the repeated measures ANOVAs on distress and quality of life during the course of chemotherapy revealed significant decreases in the overall level of distress as measured by the GSI, $F(3,12)=4.69, p=0.02$, and the Anxiety subscale, $F(3,12)=4.00, p=0.03$, of the BSI. Observed power to detect differences in both cases exceeded 0.70 . In both cases, distress decreased from baseline to the end of three cycles of chemotherapy. No differences were observed on the GSI and Anxiety scales at 3- and 8-month follow-up when compared with the levels observed at the end of chemotherapy.

In contrast, to the course of distress, the physical well-being scale of the FACT-G did not show significant changes from baseline over the course of chemotherapy, $F(3,13)=2.61$, $p=0.09$, ns. This primarily appears to be the result of low power to detect change (0.51). Consistent with the aforementioned findings for the GSI and Anxiety scales of the BSI, the emotional well-being scale of the FACT-G revealed a significant increase in quality of life from baseline over the course of chemotherapy. $F(3,13)=8.67, \quad p=0.002$. No differences were observed on the FACT-G emotional well-being scale when the post-third round chemotherapy score was compared with the 3- and 8-month follow-up scores using paired $t$-tests. As would be expected, significant improvements were observed in the FACT-G Physical Well-being scale when post-third round chemotherapy score was compared with 3 and 8 month follow-up scores, $t(11)=3.21, p=0.008$ and $t(10)=4.01, p=0.002$, respectively. Table 2 presents the means and standard deviations for the BSI and FACT-G scales.

\section{Symptom severity over the course of chemotherapy}

An examination of the severity of symptoms experienced by individuals as measured by the SDS revealed that overall, patients reported very low levels of problems such as feeling sick, poor appetite, pain, appearance, fatigue, and sleep over the course of chemotherapy. SDS Total score did not change significantly over the course of chemotherapy, $F(2,14)=1.36, p=0.029$, ns. That said, over the three cycles of chemotherapy, those areas that were reported to be the most disrupted were fatigue, sleep, mood and appetite. In each case, the greatest disruption in these areas occurred after the second round of chemotherapy, with a reduction by the end of the third round. Correlations between the SDS total score and the GSI at each assessment during chemotherapy revealed significant correlations after the first $(r=0.668, \quad p=0.006)$ and second $(r=0.608, p=0.013)$, but not after the third round $(r=0.0285, p=424)$. This is somewhat expected given the number of physical complaints included in the GSI.

\section{DISCUSSION}

Within the last few decades, research into the various combinations of chemotherapeutic agents has significantly increased the ability to successfully treat testicular cancer. In addition, refinements in the administration of these agents have reduced that short- and long-term side effects (e.g. nausea and vomiting) associated with chemotherapy. Such refinements have led to the increased relocation of chemotherapy administration form inpatient to outpatient settings. The impact of outpatient administration of chemotherapy on testicular cancer patients' emotional distress, 
Table 2. Means (S.D.) for BSI and FACT-G scales prior to, during, and after chemotherapy

\begin{tabular}{|c|c|c|c|c|c|c|}
\hline Variable & Baseline & $\begin{array}{l}\text { Post } \\
\text { 1-month }\end{array}$ & $\begin{array}{l}\text { Post } \\
\text { 2-month }\end{array}$ & $\begin{array}{l}\text { Post } \\
\text { 3-month }\end{array}$ & $\begin{array}{l}\text { 3-month } \\
\text { follow-up }\end{array}$ & $\begin{array}{l}\text { 8-month } \\
\text { follow-up }\end{array}$ \\
\hline \multicolumn{7}{|c|}{ Brief Symptom Inventory (BSI) } \\
\hline Somatization & $\begin{array}{c}54.07 \\
(10.42)\end{array}$ & $\begin{array}{l}55.67 \\
(6.83)\end{array}$ & $\begin{array}{l}59.12 \\
(5.00)\end{array}$ & $\begin{array}{l}52.00 \\
(8.77)\end{array}$ & $\begin{array}{l}48.00 \\
(9.52)\end{array}$ & $\begin{array}{l}51.27 \\
(8.76)\end{array}$ \\
\hline Depression & $\begin{array}{c}54.53 \\
(10.08)\end{array}$ & $\begin{array}{l}53.33 \\
(9.05)\end{array}$ & $\begin{array}{l}52.25 \\
(9.25)\end{array}$ & $\begin{array}{l}51.30 \\
(9.55)\end{array}$ & $\begin{array}{l}48.67 \\
(6.08)\end{array}$ & $\begin{array}{c}52.73 \\
(10.42)\end{array}$ \\
\hline Anxiety & $\begin{array}{c}58.13 \\
(11.17)\end{array}$ & $\begin{array}{l}52.53 \\
(9.28)\end{array}$ & $\begin{array}{l}48.37 \\
(7.79)\end{array}$ & $\begin{array}{c}50.50 \\
(10.38)\end{array}$ & $\begin{array}{l}45.33 \\
(7.08)\end{array}$ & $\begin{array}{c}51.64 \\
(13.40)\end{array}$ \\
\hline Hostility & $\begin{array}{c}54.27 \\
(11.08)\end{array}$ & $\begin{array}{l}52.13 \\
(9.41)\end{array}$ & $\begin{array}{l}54.31 \\
(8.57)\end{array}$ & $\begin{array}{l}52.00 \\
(9.46)\end{array}$ & $\begin{array}{l}47.92 \\
(9.02)\end{array}$ & $\begin{array}{c}50.55 \\
(10.60)\end{array}$ \\
\hline GSI & $\begin{array}{c}54.67 \\
(12.36)\end{array}$ & $\begin{array}{l}52.73 \\
(9.79)\end{array}$ & $\begin{array}{l}53.25 \\
(8.64)\end{array}$ & $\begin{array}{l}50.80 \\
(9.48)\end{array}$ & $\begin{array}{l}46.25 \\
(9.51)\end{array}$ & $\begin{array}{c}49.27 \\
(13.65)\end{array}$ \\
\hline \multicolumn{7}{|c|}{$\begin{array}{l}\text { Functional Assessment of Cancer } \\
\text { Therapy-General }(F A C T-G)\end{array}$} \\
\hline Physical well-being & $\begin{array}{l}25.12 \\
(3.28)\end{array}$ & $\begin{array}{l}24.16 \\
(3.14)\end{array}$ & $\begin{array}{l}21.37 \\
(5.49)\end{array}$ & $\begin{array}{l}24.10 \\
(2.56)\end{array}$ & $\begin{array}{l}26.42 \\
(3.37)\end{array}$ & $\begin{array}{l}26.36 \\
(1.96)\end{array}$ \\
\hline Social/family well-being & $\begin{array}{l}24.09 \\
(3.82)\end{array}$ & $\begin{array}{l}24.04 \\
(3.85)\end{array}$ & $\begin{array}{l}24.91 \\
(3.26)\end{array}$ & $\begin{array}{l}24.70 \\
(1.57)\end{array}$ & $\begin{array}{l}25.84 \\
(2.25)\end{array}$ & $\begin{array}{l}25.50 \\
(3.47)\end{array}$ \\
\hline Emotional well-being & $\begin{array}{l}14.75 \\
(2.84)\end{array}$ & $\begin{array}{l}16.81 \\
(3.12)\end{array}$ & $\begin{array}{l}17.62 \\
(2.42)\end{array}$ & $\begin{array}{l}17.40 \\
(3.24)\end{array}$ & $\begin{array}{l}18.33 \\
(1.72)\end{array}$ & $\begin{array}{c}22.91 \\
(19.15)\end{array}$ \\
\hline Functional well-being & $\begin{array}{l}18.86 \\
(6.01)\end{array}$ & $\begin{array}{l}20.31 \\
(4.76)\end{array}$ & $\begin{array}{l}18.73 \\
(5.53)\end{array}$ & $\begin{array}{l}21.50 \\
(3.31)\end{array}$ & $\begin{array}{l}24.00 \\
(5.36)\end{array}$ & $\begin{array}{c}22.91 \\
(4.55)\end{array}$ \\
\hline Total FACT-G & $\begin{array}{c}90.15 \\
(12.64)\end{array}$ & $\begin{array}{c}92.77 \\
(11.22)\end{array}$ & $\begin{array}{c}89.32 \\
(14.96)\end{array}$ & $\begin{array}{l}94.60 \\
(8.21)\end{array}$ & $\begin{array}{c}102.01 \\
(9.73)\end{array}$ & $\begin{array}{c}99.95 \\
(10.64)\end{array}$ \\
\hline
\end{tabular}

quality of life, and symptom distress has not yet been studied. The current study was designed to examine longitudinally the emotional distress, quality of life, and symptom distress ratings of patients before, during, and after three rounds of chemotherapy.

Consistent with previous research with cancer patients (Derogatis et al., 1983; Zabora et al., 2001), results from the current study indicate that while the majority of testicular cancer patients have average levels of distress that do not differ from a healthy population (Derogatis, 1992), a sizeable proportion (approximately $30 \%$ in the current sample) exhibit significantly higher levels of distress at pre-treatment baseline. This proportion is consistent with the majority of reports examining distress in cancer patients (Derogatis et al., 1983; Farber et al., 1984; Trask et al., 2001; Stefanek et al., 1987). In addition, increasing distress was associated with lower social/family well-being and lower levels of emotional well-being. Psychologists or other mental health care professionals may be of benefit to those individuals who report levels of distress and reductions in QOL exceeding pre-identified cutoffs.

Of greater interest is the finding that distress was accompanied by increased levels of anxiety at baseline, but that both decreased over the course of chemotherapy, a finding consistent with finding by Jacobsen et al. (1993). We suggest that this represents anticipatory anxiety and distress that is likely the result of individuals fearing what they may experience as a result of chemotherapy; levels that decrease once individuals start treatment. This observation is supported by the overall lack of problems in such areas as nausea, fatigue, sleep, and appearance reported by patients during their chemotherapy. Over the course of chemotherapy, minimal symptom distress was reported. As noted by the increase and subsequent decrease in symptom distress following the second and third rounds of chemotherapy, respectively, it appears that any symptom distress that became present was successfully addressed with antiemetics with minimal emotional distress associated with it. Moreover, the decreases in emotional distress and improvements in quality of life observed 
during chemotherapy continued up to the 8-month follow-up. For oncologists and others on the health care team, these results suggests that additional education efforts conducted prior to chemotherapy on the likely course of treatment and side effects may reduce anxiety in testicular cancer patients.

Several caveats should be noted. First, the study did not include either a control population of healthy subjects or a comparison group of either a different population of cancer patients receiving chemotherapy or a group of testicular cancer patients receiving a different treatment. As such, no direct comparisons can be made within this study. Despite this, however, the results of the current study, in both the average ratings of distress and 'caseness' (i.e. proportion of distressed participants), are consistent with those reported for other cancer patients (Derogatis et al., 1983; Zabora et al., 2001; Stefanek et al., 1987). A second caveat is the fact that because the results of the current study are longitudinal, there is greater opportunity for missing data. As an example, although 16 patients provided baseline information, only 10 patients provided data at every timepoint through the 8 month follow-up. This attrition, in addition to the fact that only 16 patients were accrued over a two-year period, argues for the need for multi-site studies that will allow for increased accrual and increased efforts to obtain data from participants throughout the study period. A third limitation is the limited sample size. Initial power calculations for this study suggested that in order to detect a $20 \%$ reduction using the GSI subscale during the course of chemotherapy with $90 \%$ power with a type 1 error of $5 \%, 81$ patients would be required. During the pilot study, $51-82 \%$ power was expected for the types of comparisons being performed. The lack of power was observed in several calculations, although exceeded $70 \%$ in at least one. Nevertheless, it points to the need for a larger study that utilizes several collection sites to obtain the number of patients needed in a reasonable amount of time. Finally, the fact that only one clinic was utilized further limits the potential generalizability of the results. Further studies using both community hospitals and large medical centers would provide additional information as to whether the limited symptom distress reported in this study was a function of the setting.

Despite the limited sample size, the results from the current study identify several important points for further exploration. The first is that individuals frequently display anticipatory anxiety prior to starting chemotherapy. Although not explored in the current study, it will be important for future studies to determine whether this has an effect on variables such as decision-making or involvement with treatment. The second is that this study presents, to our knowledge, the first assessment of emotional and symptom distress, and quality of life longitudinally through the course of chemotherapy. While larger samples are clearly needed before making firm conclusions, the tentative interpretation is that social and emotional distress is not increased during chemotherapy in testis cancer patients being treated on an outpatient basis at a University Medical Center, Longer term evaluations are necessary to determine if the adjustment seen during treatment is maintained in the years following treatment when some of the longer term side effects of chemotherapy may occur.

\section{ACKNOWLEDGEMENTS}

The measure was supported in part by Cancer Center Support Grant 5 P50 CA46592 of the University of Michigan Comprehensive Cancer Center.

\section{REFERENCES}

Andrykowski M, Redd W, Hatfield A. 1985. Development of anticipatory nausea: a prospective analysis. $J$ Consult Clin Psych 53: 447-454.

Arai Y, Kawakita M, Hida S, Terachi T, Okada Y, Yoshida O. 1996. Psychosocial aspects of longterm survivors of testicular cancer. J Urol 155: 574-578.

Boulet J, Boss MW. 1991. Reliability and validity of the Brief Symptom Inventory. Psychol Assess 3: 433-437.

Bovbjerg D, Redd W, Maier L et al. 1990. Anticipatory immune suppression and nausea in women receiving cyclic chemotherapy for ovarian cancer. $J$ Consult Clin Psych 58: 153-157.

Brada M, Horwich A, Peckham MJ. 1987. Treatment of favorable-prognosis nonseminomatous testicular germ cell tumors with etoposide, cisplatin, and reduced dose of bleomycin. Cancer Treat Rep 71(6): 655-656.

Cella D, Tulsky D, Gray G et al. 1993. The functional assessment of cancer therapy (FACT) scale: development and validation of the general measure. $J$ Clin Oncol 11: 570-579. 
Cella D. 1994. F.A.C.T. Manual (Version 3). RushPresbyterian-St. Luke's Medical Center: Chicago, 111.

Cullen M, Stenning S, Parkinson M et al. 1996. Shortcourse adjuvant chemotherapy in high-risk stage I nonseminomatous germ dell tumors of the tests: A Medical Research Council Report. J Clin Oncol 14: 1106-1113.

Dearnaley DP, Horwich A, A'Hern R et al. 1991. Combination chemotherapy with bleomycin, etoposide and cisplatin (BEP) for metastatic testicular teratoma: long-term follow-up. Eur J Cancer 27(6): 684-691.

Derogatis L. 1992. The Brief Symptom Inventory (BSI) administration, scoring and procedures manual-II (2nd edn). Clinical Psychometric Research: Baltimore.

Derogatis L, Melisaratos N. 1983. The brief symptom inventory: An introductory report. Psychol Med 13: 595-605.

Derogatis LP, Morrow GR, Fetting J et al. 1983. The prevalence of psychiatric disorders among cancer patients. JAMA 249: 751-757.

Farber DM, Wienerman BH, Kuypers JA. 1984. Psychosocial distress in oncology outpatients. $J$ Psychosoc Oncol 2: 109-118.

Freidenbergs I, Gordon W, Hibbard M, Diller L. 1980. Assessment and treatment of psychosocial problems of the cancer patients: A case study. Cancer Nurs 3: 111-119.

Golden S, Horwich C, Lockrich J. 1980. Chemotherapy and you (DHEW Publication No. (NIF) 77-1136). National Institutes of Health: Bethesda MD.

Heidenreich A, Hofmann R. 1999. Quality of life issues in the treatment of testicular cancer. World $J$ Urol 17: $230-238$.
Jacobsen P, Bovbjerg D, Redd W. 1993. Anticipatory anxiety in women receiving chemotherapy for breast cancer. Health Psychol 12: 469-475.

McCorkle R, Young K. 1978. Development of a symptom distress scale. Cancer Nurs 1: 373-378.

Meyerowitz B. 1980. Psychosocial correlates of breast cancer and its treatment. Psych Bull 87: 108-131.

Nasse R, Carli T, Curtis G, Kleinman P. 1980. Pretreatment nausea in cancer chemotherapy: A conditioned response? Psychosom Med 42: 33-36.

Penman DT, Holland JC, Bahna GF et al. 1984. Informed consent for investigational chemotherapy: patients' and physicians' perceptions. J Clin Oncol 2(7): 849-855.

Redd W, Andresen G, Minagawa R. 1982. Hypnotic control of anticipatory emesis in patients receiving cancer chemotherapy: J Consult Clin Psych 50: 14-19.

Stefanek ME, Derogatis LP, Shaw A. 1987. Psychological distress among oncology outpatients. Psychosomatics 28: 530-539.

Trask PC, Paterson AG, Hayasaka S, Dunn R, Riba M, Johnson T. 2001. Psychosocial characteristics of individuals with non-stage IV melanoma. J Clin Oncol 19: $2844-2850$.

van Komen R, Redd W. 1985. Personality factors associated with anticipatory nausea/vomiting in patients receiving cancer chemotherapy. Health Psychol 4: 189-202.

Williams SD, Einhorn LH. 1982. Clinical stage I testis tumors: the medical ancologist's view. Cancer Treat Rep 66(1): 15-18.

Zabora J, Brintzenhofeszoc K, Curbow B, Hooker C, Piantadosi S. 2001. The prevalence of psychological distress by cancer site. Psycho-Oncology 10: 19-28. 